\title{
Inspection Capabilities for Enhanced Ship Safety
}

\author{
I. Lazakis, G. Theotokatos, N. Barltrop \\ Dpt. of Naval Architecture, Ocean and Marine Engineering, University of Strathclyde, Glasgow, UK
}

\begin{abstract}
The INCASS (Inspection Capabilities for Enhanced Ship Safety) project brings together experienced partners to tackle the issue of ship inspection, providing access to information related to ship surveys independent of the ship flag state and inspection regime. Moreover, it incorporates enhanced and harmonized cooperation of maritime stakeholders targeting to avoid ship accidents, promote maritime safety and protect the environment. The INCASS consortium brings an innovative solution to the integration of monitoring, inspection, data gathering, risk analysis and management and Decision Support for ship structures, machinery and equipment in an efficient and collaborative manner. INCASS project introduces the enhanced inspection of ship structures employing robotic platforms, providing real time data, incorporating Structural and Machinery Risk Analysis (SRA and MRA), enhanced central database and Decision Support System for structures and machinery for continuous monitoring and risk analysis. This paper demonstrates the key features of INCASS project methodology as well as tools development.
\end{abstract}

\section{INTRODUCTION}

In the day-to-day ship operations, structural and machinery failures may lead to major accidents, endangering crew and passengers lives onboard, posing a threat to the environment, damaging the ship itself and having a great impact in terms of business losses. Moreover, with the introduction and building of a big number of new ships, their monitoring and inspection from both regulatory bodies and Classification Societies has become more difficult in order to obtain the optimum inspection results and eliminating the hazards posed by high-risk and sub-standard ships.

In this respect, the INCASS (Inspection Capabilities for Enhanced Ship Safety) project brings together a range of experienced and dedicated partners in order to tackle the issue of ship inspection by providing access to information related to ship surveys independent of the ship's flag and inspection regime and incorporate enhanced and harmonized cooperation of maritime stakeholders aiming to avoid ship accidents, promote maritime safety and protect the environment (EC, 2009). The INCASS partners include universities such as the University of Strathclyde Glasgow (USG), Universitat De Les Illes Balears (UIB), Classification Societies such as Lloyd's Register EMEA (LR), RINA Services SPA, Bureau Veritas (BV), ship owners /managers (Danaos Shipping Company and AP\&A) service providers (Glafcos Marine, Atlantec Enterprise Solutions GMBH (AES), Technicas Y Servicios De Ingenieria S.L. (TSI), Shipcon) and research institutes such as Deutsches Forschungszentrum Fuer Kuenstliche Intelligenz GMBH (DFKI). The INCASS consortium brings an innovative solution to the ship inspection regime through the introduction of enhanced inspection of ship structures based on robotic platforms, providing ship structures and machinery monitoring with real time information using 'intelligent' sensors and incorporate Structural and Machinery Risk Analysis.

Moreover, INCASS introduces Condition Based inspection tools and methodologies, reliability and criticality based maintenance, providing an enhanced Central Database including ship structures and machinery by developing a Decision Support System (DSS) for ship structures and machinery for continuous monitoring and risk analysis and management of ship operations.

The INCASS concept, through the utilization of some of Europe's leading companies and institutions, both in the consortium and advisory board, in various fields including ship inspection, ship operations, condition monitoring, development of advanced tools and methodologies, makes a significant contribution at European and international level in terms of enhancing ship inspections, and thus achieving the identification of high risk or sub-standard shipping operations.

Hence, this paper is structured among various sections. The first section provides the fundamental aspects of INCASS project, followed by the literature review on Condition Based Maintenance (CBM) and well known condition monitoring assessment tools. Afterwards, the INCASS methodology is demonstrated as well as the employed tools that the methodology consists. Lastly, the project's impact in marine industry is presented as well as considerations for the progress work. 


\section{RESEARCH BACKGROUND}

Ship accidents and near misses can be frequently attributed to the failure of structures and machinery. Accordingly, the latter increases the risk for crew and passengers' injuries and fatalities, environmental damage and pollution, damage or total loss of the ship and its equipment as well as disruption of the ship's operations which consequently lead to operational losses. Additionally, the maritime regulatory and administration authorities such as Flag states, Port State Control authorities and Classification Societies have increased their cooperative efforts towards the promotion of safe, secure and environmental friendly ship operations over the last years.

On top of the above, ship managers/operators still try to find a way to combine the rich practical knowledge acquired in the actual marine field with the technological advances stemming from the relevant information technology sector in an effective way. The latter comes in addition to the effects of not applying the appropriate maintenance sequence onboard a ship. Moreover, when repair works and/or spare parts are needed onboard the vessel, they have to be planned well in advance as the ship sails in different geographical locations, thus with significant functional/access restrictions.

Besides the above, the overall risk analysis, risk management and maintenance process in the maritime sector still lacks the element of applying and implementing technologically advanced tools in contrast to applications in other industrial sectors such as the nuclear and aerospace industry which provide real-time monitoring (e.g. condition monitoring tools and techniques). In this case, condition based procedures in the maritime industry are not well established yet (Imarest, 2011).

However, various developed methodologies can be found in literature. For instance, Lazakis et al. (2010) introduce a new maintenance management approach, particularly referring in the appraisal of the reliability and criticality characteristics of a vessel, thus increasing the vessel's operational efficiency. In Straub et al. (2006) the Risk Based Inspection (RBI) application is presented regarding fatigue deterioration for offshore fixed steel structures and floating, production, storage and offloading vessels (FPSO's). Ku et al. (2004) discussed the implementation of riskbased inspection plans regarding the strength and fatigue assessment of a floating production unit (FPU) located in offshore West Africa while Turan et al. (2009) also presented a methodology for examining the effects of hull structure repairs on the life cycle cost of ships.

\subsection{Hull Condition Assessment (HCA)}

HCA is a critical activity in the maritime industry as it is straightforwardly linked to the ship's functional condition and the safety preconditions mandated for the ship herself and the onboard personnel. On time identifications of defects has also a significant monetary value for the ship operators as it allows better scheduling of maintenance activities and prohibits failure propagation effects, thus minimizing the risks. HCA is currently performed under two directions. Firstly, the periodic Classification surveys, during which the hull status is compared to some predefined nominal values (with metrics like hull and structural members' thicknesses or extent of rust or pitting). Whereas, Condition surveys are performed under the ship owner's/operator's responsibility and usually have as objective the scheduling of the repair activities.

This need has been identified in the maritime transport sector and has introduced two EC funded research paradigms, namely the HCA-Flagship (Emmett et al., 2011) effort and RISPECT (RiskBased Expert System for Through-Life Ship Structural Inspection and Maintenance and New-Build Ship Structural Design) project (Barltrop et al., 2010), which offer decision support tools to assist in the decision making process, prediction for possible areas of defect depending on parameters like the ship's type, age and size, with knowledge and information collected from past experiences (databases) and updated with current survey data.

RISPECT project combined the traditional experience based inspection method with the first-principles, statistical analysis, for safe, cost-effectiveness structural inspection, repair and design rule improvement of existing ships (RISPECT, 2012). It provided aids to the structural integrity management of ships that can be succeeded by optimizing the overall management of shipping operations. More specifically, the project developed tools for assessing structural loads, stresses and strength. Additionally, a standard database structure was also created in order to be accessed by Classification Societies and ship operators. This was populated with sanitized data from survey results in order to avoid duplications and sensitive information being released, while at the same time maintaining the significance of the collected information. However, no real-time information was collected. Moreover, the analysis performed was not centered on risk-based approaches, thus identifying the critical ship structural areas and consequently ships. This is an area at which the INCASS project aims for.

Furthermore, the main goal of existing systems was to assist with the detection of the loss of the external coating, detection of accelerating corrosion of outer hull, weld inspection, etc. Most part of these systems does not use visual sensors to perform the inspection and if they use them, the output of the system is a mosaic to be surveyed by a human expert, so that no on-line defect inspection is performed. In this respect, the scope of the MINOAS (Marine Inspection 
rObotic Assistant System) project comprised the inspection of both dry and wet areas of the vessel (e.g. flooded ballast tanks or external hull) (Biduli et al., 2011). Moreover, the project was not limited to teleoperated floating tethered vehicles and considered a varied set of robotic technologies with different locomotion capabilities and different degrees of autonomy. In more detail, the MINOAS concept comprised aerial vehicles, magnetic crawlers, and ROVs. The aerial vehicle, due to its mobility, was intended to provide a fast overview of the state of the structure under inspection, e.g. a cargo hold of a ship.

\subsection{Condition Based Maintenance (CBM)}

CBM tries to avoid unnecessary inspections for machinery and structure which are in technically perfect condition and to minimize the amount of unexpected machinery breakdowns and structure failures. This methodology seeks to know the actual state of the machinery by means of the measurement and suitable analysis of a list of specific variables and parameters without interfering in the normal operation of the system. This leads to know if the system is working properly, estimate when the failure is likely to happen and what the cause has been or will be, allowing to programme the maintenance tasks, thus to reduce the cost associated to them, and to minimize the inherent risks and not expected costs of an unforeseen machinery failure.

More specifically, the key concept of the machinery CBM methodology rests on that every machine, when it works properly, has a determined level of vibration, noise or whatever parameter, considered as "base state" and when a defect appears, even in early stages, leads to a characteristic increment of the level which permits to identify it and evaluate its severity. The experience has revealed that vibration monitoring is one of the most powerful tools to control properly the condition of the rotating and oscillating machinery. However other techniques have been developed, in some cases, to provide support to the first one, in other cases to get new and necessary information, which allows the identification of defects mainly in static equipment, electrical and internal combustion engines. Some of the tools necessary to develop a successful Condition Based Maintenance programme are mentioned next.

\subsubsection{Vibration Monitoring}

The various vibration frequencies in a rotating machine are directly related to its geometry and operating speed (Al-Najjar, 1996). By knowing the relationship between the frequencies during optimal operation of machinery, it is easy to identify at an early stage any types of defects and take remedial action well before the equipment is damaged or has to be taken out of operation. Among others, vibration monitoring can detect unbalanced rotating machinery parts, excess sleeve or bearing wear, misalignments, damaged gear teeth, and damaged bearings. This technique applies also to Propulsion Diesel engines, Electrical Generator engines, Gear boxes, Main steam turbines, Pumps and Motors Compressors, Turbochargers, Generators, Propellers and Shafting \& water jets, covering most equipment onboard a ship. It has to be noted that a number of structural defects have their origin in excessive vibration from machinery, as mentioned above, so its early identification and rectification ensures the good condition and longevity of associated structures. All the sensors used to measure vibration, convert the physical magnitude (in terms of displacement, velocity or acceleration depending on the kind of sensor) into a proportional electrical signal that can be split into its fundamental frequencies.

\subsubsection{Thermography}

This technique measures absolute or relative temperatures of the different parts of the machine (Bagavathiappan et al., 2013). Abnormal temperatures indicate developing problems. Any friction or coupling problem generates overheating and any increment in the electric resistivity results in "hot spots". The most common contact methods use thermocouples and thermometers. However non-contact methods using infrared sensors have become a desirably alternative over the conventional ones (Budweg, 2012). This technique can be applied to Steam turbines, Turbochargers, Diesel engines, Electrical engines, Generators.

\subsubsection{Lubricating oil analysis}

This tool is aimed at controlling the state of the lubricant, the level of degradation of the different components of the machine and the presence of moisture and water by analyzing the lubricating oil (Jiang and Yan, 2008). Its specific application to diesel engines, compressors and gear boxes, besides to the advantages related to the optimization of the lubricant oil changes, can confirm the diagnostic made with others tools, in particular with vibration monitoring. This technique monitors the following parameters: kinematic viscosity, humidity/water content, particles content, etc. giving an early indication of potential damages and malfunctions. Lubricating oil analysis can be applied to Diesel engines, Gear boxes, Steering Gears, Compressors and Steam turbines among others.

\section{INCASS METHODOLOGY}

Within the INCASS project consortium there are partners such as universities, Classification Societies, 
ship owners/ operators/ managers and service providers which are at the forefront of research and development with long experience and high expertise related to ship inspections, surveying and monitoring, data gathering and assessment as well as the development and implementation of databases and DSS. In this respect, INCASS project takes into account the achievements of both RISPECT and MINOAS projects and furthermore expand on them through the inclusion of machinery related data gathering, assessment and risk and reliability appraisal. Moreover, INCASS enhances the previous projects' framework by developing a Central Database for both structures and machinery and additionally incorporating a DSS in order to address emergency (short term) decision making in case of accidents occurring as well as supporting long term decisions.

\subsection{INCASS Project Innovations}

Overall, through the implementation of the INCASS platform, the improvements aim to develop new pattern recognition and image processing methods. INCASS employs robotic platforms and state-of-the-art technologies for vessel status data collection. Moreover, the project collects and analyses structural failure consequence data and machinery and equipment data by employing historical expert and real time monitoring data. It applies a CBM approach with respect to detection of required maintenance activities, spares logistics and approval of maintenance and repair jobs. In additional, INCASS develops Structural and Machinery Risk Analysis (SRA and MRA respectively) tools to monitor high risk ships, combined with a Central Database which will include information for structures and machinery to be available to the maritime industry for access.

\subsection{INCASS Framework}

This section demonstrates the INCASS framework as shown in Figure 1. INCASS is developed by assessing structural loads, developing a Central Database, methodology update through the use of crawling and flying robots for structural close-up inspection, transfer of visual information and data to a centralized display and expands on including a realtime condition monitoring framework onboard the ship in the first place. This occurs with the use of inspection tools for structures such as continuous monitoring with strain sensors for structures, ship's monitoring of hydrodynamic influence from the actual ship operation, enhanced robots image and data acquisition, engulfing the different operational profiles of the ship as it sails worldwide.

Accordingly, real-time monitoring is described for the ship machinery and equipment with sensors used for machinery vibration monitoring, performance monitoring of ship engines, thermal imaging for electrical panels and switchboard and other condition monitoring applications. At this point, it must be mentioned that although some of these tools and techniques are applied in the maritime industry to some extent (mostly in the offshore oil and gas industry); they are not exploited to their full capabilities. In INCASS, these are operating in a collaborative way, feeding into the main procedure for automated data collection and processing while also considering the practices that will be conveyed in the project by partners with experience and expertise in other critical safety industries (aerospace and nuclear ones).

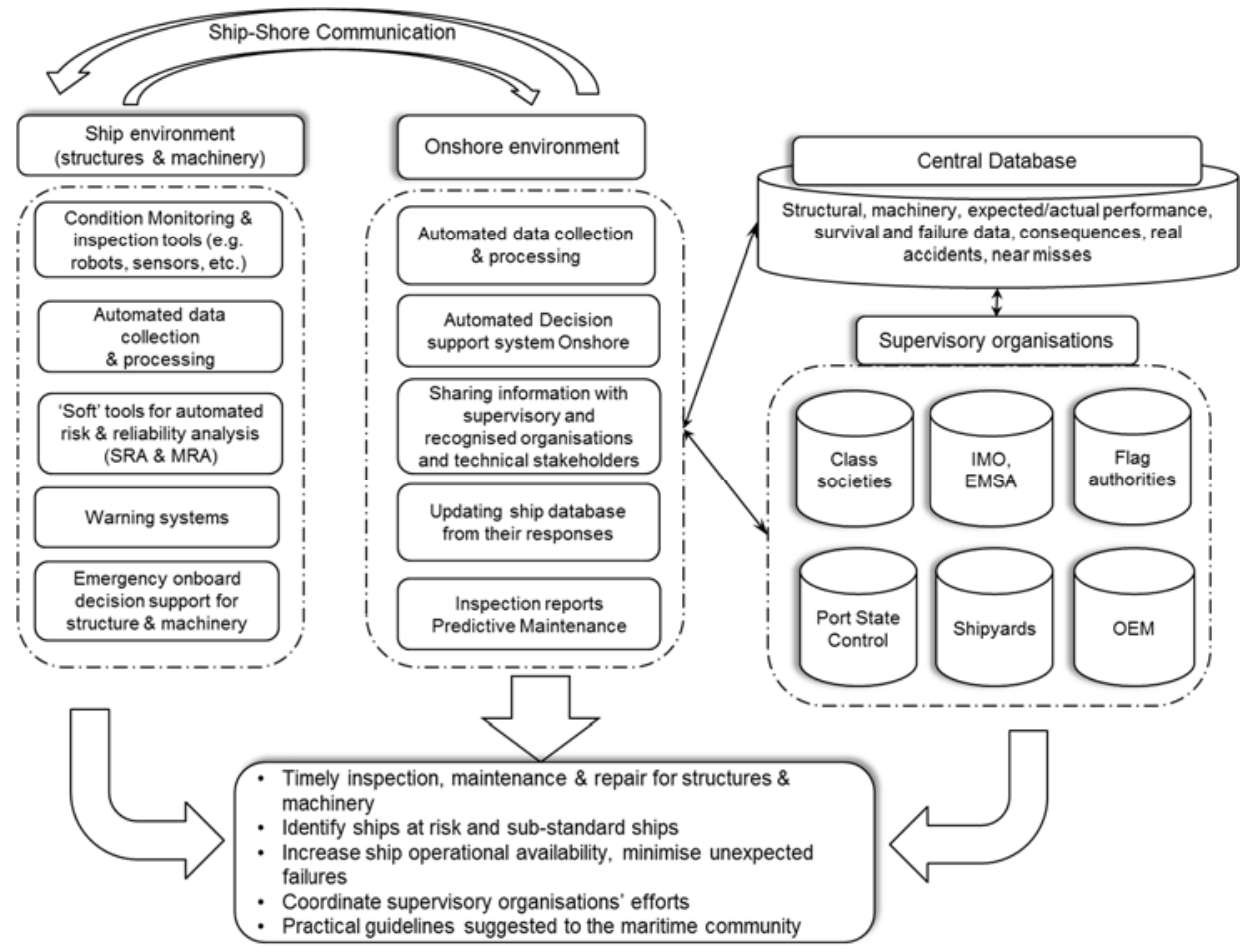

Figure 1. INCASS inspection capabilities framework. 
Moreover, soft tools for automated risk \& reliability analysis are developed for structures (Structural Risk Analysis-SRA) and machinery (Machinery Risk Analysis-MRA) using the data that are collected in the previous steps. At this stage, the assessment of the ship's structures and machinery condition is performed leading to warning systems in case of an emergency. Eventually, this leads to an onboard Decision Support tool for both structures and machinery, enabling the short-term quick decision making that the crew of the ship can face with in emergency situations. The Decision Support process is developed to utilize inspection and real-time monitoring data including a number of linguistic (experts judgement, semantic values) and numerical attributes (MTBF, failure rates, mean time to repair, etc.) supported by automatic analytical methods; such as historic and real-time monitoring and ship performance data. Moreover predictive methods are also introduced aiming at forecasting future ship performance.

On the other hand, the onshore environment consists of an automated data collection and processing tool that is fed in with real-time information based on the ship's condition of structures and machinery/equipment. It is important to note that an automated Decision Support (DS) tool will be also available so as to support the decision making on shore in need of a longer-term decision making involving and sharing information among the ship operators and technical stakeholders. The latter leads to inspection reports being produced for longer-term scheduling, including actions for maintenance and repairs of structural parts and machinery.

The results of the Decision Support tool including inspection reports and predictive maintenance tasks are eventually fed into the Central Database which are in place onshore and used for data and information storage being updated with maritime stakeholders' responses as well. In this case, the Central Database includes information for ships' structures and machinery, their expected and actual performance, survival and failure data as well as potential failure consequences and information from real accidents and near misses. This in turn enables the Central Database being continuously updated so as to include the latest information for a particular ship and fleet size.

\section{INCASS TOOLS}

This section layouts the INCASS project tools, their functionalities and innovations applied. In more detail, the data collection, Structural and Machinery Risk Analysis and decision making process are described.

\subsection{Structural and Machinery Risk Analysis}

Initially, data is gathered from a number of different sources. These refer to original inspection data, historical data from previous ship inspections and databases, previous efforts using numerical models to estimate the inspection planning as well as information from actual ship accidents and near misses. Also data is collected from external databases (e.g. UK MAIB, OREDA database), historical data including failure consequences, Mean Time Between Failures (MTBF), failure rates for individual components, inspection and maintenance intervals performed onboard, experts' data from condition monitoring campaigns onboard ships, real time monitoring through the use of intelligent sensors.

The data from the above sources will be combined in order to feed into the SRA and MRA soft tools. The SRA includes elements of the Risk Based Inspection (RBI) coupled with risk management leading to the structural inspections based on the risk analysis results. For the MRA, the RCBM (Reliability and Criticality based Maintenance) process takes place for specific machinery systems (e.g. Main Engine, Turbocharger, selected pumps and the steering gear). In this case, the less reliable and high or medium level criticality machinery systems and components are identified in a specific and measurable way so as to enable not only the ship risk management but also enable the comparison of the in-service reliability of ships overall through a common metric such as the Overall Equipment Effectiveness so that different ships can be easily comparable and high risk ships identified. The above is also provided in the form of guideline suggestions to the maritime authorities for further application throughout the fleet numbers.

Both the SRA and MRA are able to interact with both the onshore stakeholders (maritime authorities, Classification Societies, ship operators/s) through the INCASS Central Database and the onboard bridge and engine room teams in order to reach a short-term Rapid Emergency Decision Support (REDS) system for structures and machinery as well as a long-term DSS for a maintenance management framework. The short-term REDS includes the data mining process in order to understand the systems in question and gain knowledge from other experiences while providing for short term decision making employing the SRA and MRA tools giving warnings of impending high risk and eventually providing decision support following a ship incident. For the long-term decision support, a maintenance management system is employed to detect the required maintenance activities, arrange for the approval of maintenance and repair jobs to be performed onboard as well as enable the provision for spare parts and logistics requirements from OEMs and suppliers. The above maintenance management procedure includes the feedback and re- 
quirements of Class and regulatory authorities following the initial appraisal of the condition of the ship's structure and machinery.

\subsection{Central Database}

Regarding the Central Database, the collection of structural \& machinery data and risk analysis takes place through the use of a series of new developed tools. The system is initialized by importing design information. Possible data sources are listed as existing design information from Class, CAD design information (3D models or drawing based), specifications, and tabular information like inventories or part lists. The HCM adapter will allow import of detailed structural design and life-cycle information (Jaramillo, 2007).

Once a minimum set of mandatory information is available, initial risk analysis and assessment calculations can be carried out. This enables the system to be operated in decision support mode. During ship operation, new information can be added on-board as measurement and recorded sensor data becomes available. Due to the volume and nature measure realtime data, pre-processing and filtering will occur before the data is persistently stored in the system. Similarly, results from inspections (e.g. as provided by inspection companies) can be added, e.g. by importing results using HCM data Whenever new data is available, the risk analysis and assessment can be repeated, resulting in new risk analysis results. Alternatively, in an emergency situation or in case of a spontaneous failure of some component(s), a faster emergency risk assessment is possible. Such failure information can also be entered interactively, which would all support what-if types of analysis.

\subsection{Structural modelling and analysis}

In addition to the existing inspection data within the database, the inspection data obtained from robots will also be included to support the calibration process. Furthermore, the real-time information obtained from robots will be used to check the current-status of the ship structure for the emergency DSS.

In this case, the INCASS structural platform of tools enhances the existing tools and methodology with new ones. First of all, the creation of interface and analysis for the data is introduced that will be collected through the robotic applications during the ship inspection. Furthermore, a tool for ship hydrodynamic and structural analysis is developed. Additionally, analysis and consolidation of the structural data is established through the various data acquisition methods.

\subsection{Machinery tools and methodology}

In a similar manner, tools are developed as part of the machinery and equipment set of tools and methodologies and they feed in their results and data in the machinery and equipment database. These include systems according to the ship types that are investigated through the INCASS project (i.e. tankers, bulk carriers and container ships) and include the Main Engine, Turbocharger, selected pumps and the steering gear.

Accordingly, the results from the integration of the numerical models and the failures identification based on reliability and criticality calculations are integrated in the machinery and equipment assessment framework. The ship systems examined above feed in with data to the machinery and equipment database toolbox. This in turn includes the calculations and risk and reliability analysis performed so as to identify the components and systems prone to failure as well as assess their criticality level. In this case, the decision support process is also activated in order to inform the onboard and onshore personnel of the available optimum suggestions.

As an addition to the above, one of the outcomes of the INCASS framework is the development of practical guidelines regarding ship inspection in terms of structures and machinery so as to focus the inspection effort at the critical and most sensitive areas of the ship. The guidelines will be addressed to both European (e.g. EMSA) and international authorities (e.g. IMO). Concurrently, the high risk ships will be easier monitored and their operations controlled, contributing to the European and international efforts for minimization and avoidance of ship accidents with important results on safety and the environment.

\subsection{Preliminary results}

INCASS project consortium includes a number of partners such as universities, Classification Societies as well as ship operators, managers, owners and service providers. Thus, CM requirements vary among the project stakeholders. Due to different CM necessities, the project members' requirements are assessed leading to the final machinery and equipment selection (INCASS, 2014).

At first, Classification Societies' input was examined. Their role was to check that safety standards of ships are met throughout surveys, inspections, tests and controls. On the other hand, ship operators, managers, owners and service providers support that major machinery breakdown may lead to major/minor repair cost as well as increasing ship systems downtime. The reasons for monitoring and collecting information on ships from their viewpoint are related to environmental protection, safety of personnel onboard, compliance, Class statutory requirements and reduction of business risk and cost. 
As it can be summarized from the INCASS stakeholders requirements, Classification Societies are mostly focused on the ship's functionality ensuring safety and environmental protection among others. Whereas, ship operators, managers, owners and service providers are focused on ship's operation and availability ensuring business efficiency and safety.

\subsubsection{Classification Societies requirements}

The role of Classes is to check that safety standards of ships are met throughout surveys, inspections, tests and controls. As long as ship machinery and equipment monitoring technologies provide relevant information that can demonstrate that condition of equipment is acceptable to ensure ship safety, they can be used as a complementary means for Classes to confirm that machinery, equipment and appliances comply with the applicable rules and remain in satisfactory condition. Moreover, when CM techniques are properly applied, they can enhance decision support and facilitate the work of Class surveyors, thus they can get an objective opinion on the condition of a surveyed item/system of machinery and equipment without dismantling it. A Classification survey is a visual examination that normally consists of an overall examination of the items for survey, detailed checks of selected parts and witnessing tests, measurements and trials where applicable. According to Classification Societies' input, the most critical failure records are distributed among Oil Tanker, Bulk Carrier and Container ship categories respectively. Moreover, failure records by ship and machinery type indicate the Main Engine (M/E), propeller unit, and the steering gear as the most critical due to higher failure occurrence.

\subsubsection{Ship operators/managers/owners/service pro- viders requirements}

All ship related stakeholders have the greatest interest in collecting ship machinery and equipment data for a number of reasons. First and foremost a major machinery breakdown leads not only to major/minor repair cost, but also and probably most importantly increases ship systems downtime through which valuable ship earning may be lost and/or could lead to environmental cost. From ship operators/ managers/ owners/ service providers' perspective, the reasons for monitoring and collecting information on ships are related to environmental protection, safety of personnel onboard, compliance, Class Statutory requirements, minimizing business risk, and minimizing costs.

In INCASS stakeholders' requirements specification, a comparative research study takes place. The systems that project members agreed on their operational importance ensuring all considered requirements are summarized as the Main Engine $(\mathrm{M} / \mathrm{E})$,
Turbo-chargers (T/C), critical selected pumps (including steam powered tanker ship cargo pumps) and steering gear system.

\section{DISCUSSION AND CONCLUSIONS}

INCASS project contributes towards the development of methodologies and tools which can enable recognized organizations and regulatory authorities to assess and upgrade their risk management processes. The project targets to enable more efficient coordination of inspection scheduling, and monitoring practices particularly by sharing information on incidents and near loss cases. Moreover, it contributes towards the classification and identification of preventive actions over time, by performing risk analysis, involving risk control options, cost benefit analysis and decision making recommendations. Furthermore, INCASS aims to improve technologies in inspection, repair and verification of ship structures, by considering vessel condition information through real time information from 'intelligent' sensors, enabling the awareness of more targeted and time efficient inspection processes.

The Structural Risk Analysis (SRA) and Machinery Risk Analysis (MRA) tools improve and upgrade the existing regulatory risk management processes as they provide an easily accessible way to determine the vulnerability of ships at any time in a quick and efficient way. In this case, the quality of the services that recognized inspection organizations offer are majorly improved, allowing for comprehensive horizontal access to ship inspections, data gathering and definition of the risk profile of ships.

Moreover, with the development of the Central Database, the overall screening of information regarding different ships types is available in a direct and continuous way. This is available at both a single ship and entire fleet level so as to enable the through life ship monitoring regardless of the ship ownership and Flag regime. The latter eventually decreases the cost for costly and time-consuming ship inspections for both the ship operators' side and the Classification Societies and other inspection organizations involved. Additionally, the Central Database is also continuously upgraded regarding the most recent information and knowledge from existing databases of Port State Control authorities and their inspection results in a seamless way.

In addition to the above, the DSS for structural members and machinery provides additional benefits related to both constant and successful cooperation among maritime stakeholders (Class, Port State control, operators, shipyards and OEMs) and minimization of inspection time and cost. As the developed DSS includes both short-term emergency response for the crew onboard the ship as well as long-term decision making involving the onshore stakeholders, it 
avoids, mitigates and reduces the unexpected, costly, unsafe and environmentally unfriendly ship operations especially following a ship incident or near miss, either including structural damage (e.g. flooding of ship compartments, losing structural integrity) or machinery failure (e.g. leaking of fuel/hydraulic pipes, explosions and fire due to unexpected machinery breakdown).

In conclusion, INCASS provides a development platform for combining a range of several advanced information technology features, ranging from data management and analysis, image processing to efficient long-range communication. The management of data large volume as generated by sensors and inspection methods combines with a large scale analysis system, which also needs to maintain even larger data repositories. INCASS contributes substantially to the realization of a full scope life-cycle data representation for maritime vessels. This in turn will facilitate data analysis and data mining capabilities to be applied in ways that are not possible today. As the overall system requires an optimized combination of stateof-the-art computational equipment with advanced software solution approaches, it will lead to new findings and insights on how to implement such an environment. The project will also provide a test bed for investigating ship-to-shore communication for dataintensive applications.

\section{ACKNOWLEDGEMENTS}

INCASS project has received research funding from the European Union's Seventh Framework Programme under grant agreement no 605200. This publication reflects only the author's views and European Union is not liable for any use that may be made of the information contained herein.

\section{REFERENCES}

AL-NAJJAR, B. (1996) Total quality maintenance: An approach for continuous reduction in costs of quality products. Journal of Quality in Maintenance Engineering, 2, 4-20.

BAGAVATHIAPPAN, S., LAHIRI, B. B., SARAVANAN, T., PHILIP, J. \& JAYAKUMAR, T. (2013) Infrared thermography for condition monitoring - A review. Infrared Physics \& Technology, 60, 35-55.

BARLTROP, N., HU, L. \& HIFI, N. (2010) RiskBased Expert System for Through - Life Ship Structural Inspection. Maintenance and NewBuild Ship Structural Design. University of Strathclyde.

BIDULI, M., BRUZZONE, G., CACCIA, M., ORTIZ, A., VOEGELE, T., EICH, M., DRIKOS, L., KOVEOS, Y., KOLIVAS, E.,
SPADONI, F., VERGINE, A., TANNEBERGER, K., TODOROVA, A., GAVIOTIS, I. \& APOSTOLOPOULOU, V. (2011) The MINOAS project: Marine INspection rObotic Assistant System. Proceedings of the IEEE Mediterranean Conference on Control.

BUDWEG, M. (2012) Temperature Monitoring, Switchgear busbars, Hot Topic. Marine Maintenance Technology International, The Official Publication of Marine Maintenance World EXPO. Brussels, Belgium, Raytek Corporation.

EC (2009) Regulation (EC) No 391/2009 of the European Parliament and of the Council of 23 April 2009 - (Common Rules and Standards for Ship Inspection and Survey Organisations),. Official Journal of the European Union.

EMMETT, L., CHURCHMAN, L. \& HOOLEY, S. (2011) FLAGSHIP-HCA enables accurate hull condition forecasting for improved maintenance and investment.

IMAREST (2011) The philosophy behind condition monitoring. Marine engineers review (MER).

INCASS (2014) Deliverable D4.2 Stakeholders' data requirements. INCASS - Inspection Capabilities for Enhanced Ship Safety. EC FP7 Project.

JARAMILLO, D. (2007) Specification of HCM (Hull Condition Data Model). FP6-516561 , CAS Project.

JIANG, R. \& YAN, X. (2008) Condition Monitoring of Diesel Engines. Complex System Maintenance Handbook. Springer London.

KU, A., SERRATELLA, C., SPONG, R., BASU, R., WANG, G. \& ANGEVINE, D. (2004) Structural reliability applications in developing risk-based inspection plans for a floating production installation. 23rd International Conference of Offshore Mechanics and Arctic Engineering (OMAE). Vancouver, Canada.

LAZAKIS, I., TURAN, O. \& AKSU, S. (2010) Increasing ship operational reliability through the implementation of a holistic maintenance management strategy. Ships and Offshore Structures, 5, 337-357.

STRAUB, D., GOYET, J., SORENSEN, J. \& FABER, M. H. (2006) Benefits of risk based inspection planning for offshore structures. Proceedings of the 25th International Conference of Offshore Mechanics and Arctic Engineering (OMAE). Hamburg, Germany.

TURAN, O., OLCER, A. I., LAZAKIS, I., RIGO, P. \& CAPRACE, J. D. (2009) Maintenance/repair and production-oriented life cycle cost/earning model for ship structural optimisation during conceptual design stage. Ships and Offshore Structures, 4, 107-125. 